\title{
Harran Ovası'nda Mısır Bitkisi (Zea mays L.) için Planlanan ve Gerçekleşen Sulama Zamanı Programının Değerlendirilmesi
}

\author{
Aslı DEMIROK ${ }^{1 *}$, Gökhan İsmail TUYLU² $^{2}$ \\ ${ }^{1}$ Harran Üniversitesi, Fen Bilimleri Enstitüsü, Tarımsal Yapılar ve Sulama Anabilim Dalı, Şanlıurfa \\ ${ }^{2}$ Harran Üniversitesi, Ziraat Fakültesi Tarımsal Yapılar ve Sulama Bölümü, Şanlıurfa \\ *Sorumlu Yazar: asli_zeynep1985@hotmail.com
}

\begin{abstract}
Öz
Çalışmada, mısır bitkisi (Zea mays L.) için optimum sulama zamanı planlaması ve gerçek zamanlı optimum sulama zamanı değerlendirmesi IRSIS bilgisayar yazııımı kullanılarak yapılmışıır. Değerlendirmede 2015 yılına ait iklim değerleri ve Harran Üniversitesi araştırma alanında yürütülen deneme sonucunda Class A-Pan kabına göre elde edilen sulama suyu miktarları IRSIS bilgisayar yazılımında kullanılarak gerçek zamanlı sulama değerlendirmesi yapılmış ve planlanan mısır sulaması ile gerçekleşen mısır sulaması ilişkisi irdelenmiştir. Planlamada sulama suyu miktarı $711.1 \mathrm{~mm}$ ve sulama randımanı \% 98.9 olurken gerçekleşen sulamada sulama suyu miktarı $989 \mathrm{~mm}$ ve sulama randımanı \% 60 olarak belirlenmiştir. Uygulamada aşırı su uygulaması yapılmış ve derine sızmaya neden olunmuştur. Derine sızan su miktarı planlamada $114.2 \mathrm{~mm}$ olurken gerçekleşen sulamada $397.4 \mathrm{~mm}$ olarak bulunmuştur. Planlanan ve gerçekleşen sulamaya göre verim kaybı yaşanmamıştır.
\end{abstract}

Anahtar kelimeler: A-sınıfı buharlaşma kabı, Harran Ovası, IRSIS, Mısır.

\section{Evaluation of Planning and Actual Irrigation Time Scheduling for the Maize (Zea mays L.) Plant in Harran Plain}

\begin{abstract}
In the study, planning of optimum irrigation time and real time optimum irrigation time's evaluation for maize (Zea mays L.) was carried out by using IRSIS computer software In the evaluation, as a result of climate statics that are belong to year of 2015 and test which was performed in research area of Harran University, irrigation water that was obtained according to Class A Pan was used in IRSIS computer software and real time irrigation evaluation was carried out, relation of planned irrigation of maize and actualised irrigation of maize was examined. In the planned irrigation, amount of irrigation water was $711.1 \mathrm{~mm}$ and irrigation efficiency was $98.9 \%$; in the actualised irrigation, the amount of irrigation water was $989 \mathrm{~mm}$ and irrigation efficiency was $60 \%$. In practice, excess water application was performed and it caused leakage into the deep. Irrigation water that went to drainage in planning was $114.2 \mathrm{~mm}$ and it was $397.4 \mathrm{~mm}$ in the actualised irrigation. According to planned and actualised irrigation, there was no degradation.
\end{abstract}

Key words: Class A-Pan, Harran Plain, IRSIS, Maize,

\section{Giriş}

Toplum yaşamında ekonomik ve sosyal düzenin güvencelerinden birisi de tatlı su kaynaklarıdır. Dünyada ve Türkiye'de sınırlı ve dağınık olan tatlı su kaynakları, insanoğlu tarafından uzun yıllar sorun yaşanmadan rahatlıkla kullanılmıştır. Ancak, küresel iklim değişikliğine bağlı olarak oluşan küresel ısınma, su kaynaklarının üzerinde olumsuz etkiye neden olmuştur. Bununla beraber 
küresel ısınma, tarımsal sulamada yöntem ve sistem seçimini de etkilemiştir. Günümüzde tarımsal sulamada toprak ve su kaynaklarının korunmasını sağlayan yeni sulama teknolojilerinin kullanımı, özellikle sulama randımanı yüksek, suyu homojen dağıtan ve iş gücü gereksinimi az olan basınçlı sulama sistemleri, yaygınlaşmıştır.

IRSIS (Raes ve ark., 1988) ve CROPWAT (Smith, 1992) bilgisayar yazılımları, sulama zaman planlanması amacı ile geliştirilen ve sulama sistemlerinin işletilmesine yönelik kullanılabilen destek yazılımlardır. Bu yazılımlardan IRSIS bilgisayar yazılımı kullanılarak Şanlıurfa yöresinde yetiştirilen bazı tarla bitkilerinin yeterli ve kısıtlı su kaynağı koşulları için sulama programları, bitki desenlerine ilişkin su tüketimleri, sulama suyu ihtiyaçları, sulama tarihleri ve su verim ilişkileri belirlenmiştir (Kodal ve ark., 2003). Gediz Havzası Sarıkız Sulama Birliği'nde farklı toprak özelliklerine sahip sulama alanlarında yetiştiriciliği yapılan mısır ve bağ bitkileri için IRSIS bilgisayar yazılımı kullanılarak sulama tarihlerini, sulama aralıklarını ve sulama suyu miktarlarını içeren optimum sulama zaman planları elde edilmiştir. Diğer yandan mısır ve bağ bitkileri için su kısıtı uygulanmış, sulama tarihlerini, sulama aralıklarını ve sulama suyu miktarlarını içeren kısıtlı sulama zaman planları elde edilmiştir (Tuylu ve UI, 2015).

Sulama zamanının planlanmasındaki amaç, sulamaya başlanacak zamanın ve uygulanacak sulama suyu miktarının belirlenmesidir. $\mathrm{Bu}$ işlemlerin yapılabilmesi için tarımı yapılan bitki özellikleri, ıslatılacak toprak derinliği, toprağın kullanılabilir su tutma kapasitesi, sulamaya başlanacak nem düzeyi, her sulamada uygulanacak net sulama suyu miktarı ve bitki su tüketimi gibi bilgilere ihtiyaç vardır. Sulama zamanının planlanmasında temel ilke, toprak nemini sulamaya başlanacak nem düzeyine düştüğünde tarla kapasitesine çıkaracak kadar sulama suyu uygulamaktır (Tahmaz Koçak, 2006).

Çalışmada, 2015 yılında Harran Ovası́nı temsil edecek şekilde seçilen alanda Mısır bitkisi için (Zea mays L.) sulama zamanı planlaması yapılmış ve aynı yıl gerçekleşen sulama ile karşılaştırılmıştır. Çalışma yörede yetiştiriciliği yapan üreticilere ve sulama planlayıcılarına katkı sağlaması, sulama uygulamalarındaki hataların ortaya konması ve eksikliklerin giderilmesi yönünden önemlidir.

\section{Materyal ve Metot}

Araştırma Güneydoğu Anadolu Bölgesinin Şanlıurfa iline bağlı Harran Ovasında bulunan Şanlıurfa merkezine 8 km uzaklıktaki Harran Üniversitesi Eyyübiye Yerleşkesi deneme alanında yürütülmüştür. Deneme alanının denizden yüksekliği ortalama 464-467 m arasında olup, $37^{\circ} 08^{\prime} \mathrm{N}$ enlemi ve $38^{\circ} 46^{\prime} \mathrm{E}$ boylamı arasında yer almaktadır (Şekil 1 ).

Deneme alanının toprak $\mathrm{pH}^{\prime}$ sı 7.3 - 7.4 arasında değişen, yüzeyde organik madde \% 1.1 , derinlerde ise \% 0.8'e düşen yapıda özellik göstermektedir. IRSIS bilgisayar yazılımında planlama ve değerlendirmede kullanılan deneme alanı toprak özellikleri Çizelge 1 'de sunulmuştur. 


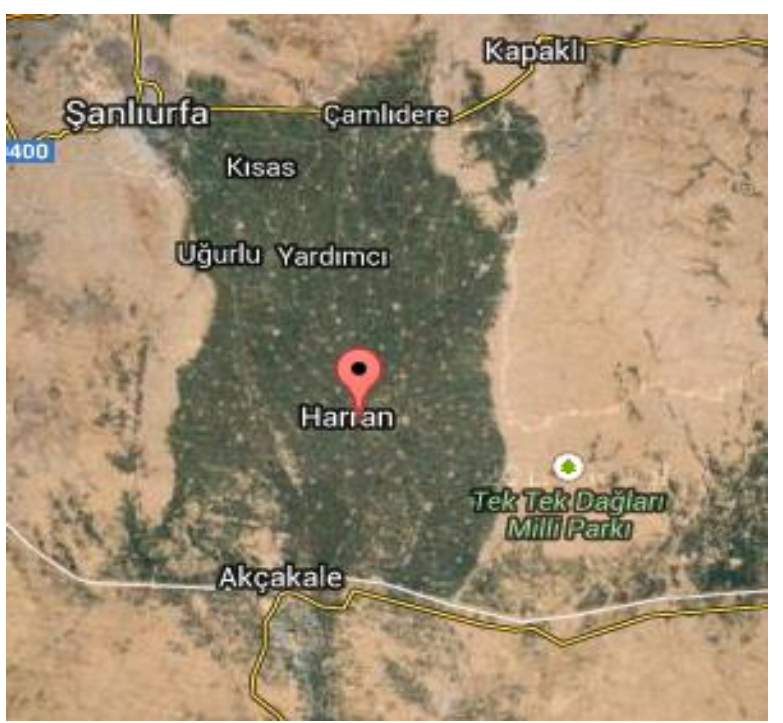

Şekil 1. Harran Ovası'nın coğrafik konumu (Özcan ve Tuylu, 2015)

Figure 1. The geographical location of the Harran Plain (Özcan and Tuylu, 2015)

Çizelge 1. Deneme alanı topraklarının bazı fiziksel ve kimyasal özellikleri (Tarı, 2015)

Table 1. Some physical and chemical properties of soil of experimental fields (Tari, 2015)

\begin{tabular}{|c|c|c|c|c|c|c|c|c|c|}
\hline $\begin{array}{c}\text { Derinlik } \\
\text { Depth } \\
(\mathrm{cm})\end{array}$ & $\begin{array}{c}\mathrm{EC} \text { e } \\
\left(\mathrm{dSm}^{-1}\right)\end{array}$ & $\begin{array}{c}\mathrm{TK} \\
\left(\mathrm{gg}^{-1}\right)\end{array}$ & $\begin{array}{c}\mathrm{SN} \\
\left(\mathrm{gg}^{-1}\right)\end{array}$ & $\begin{array}{c}\text { As } \\
\left(\mathrm{gcm}^{-3}\right)\end{array}$ & $\begin{array}{c}\text { Elverişli nem } \\
\text { Avaliable } \\
\text { moisture }(\mathrm{mm})\end{array}$ & $\begin{array}{c}\text { Kil } \\
\text { Clay } \\
(\%)\end{array}$ & $\begin{array}{c}\text { Silt } \\
\text { Silt } \\
(\%)\end{array}$ & $\begin{array}{c}\text { Kum } \\
\text { Sand } \\
(\%)\end{array}$ & $\begin{array}{c}\text { Bünye } \\
\text { Sınıfı } \\
\text { Texture } \\
\text { Category }\end{array}$ \\
\hline $0-30$ & 1.04 & 32.50 & 22.10 & 1.15 & 35.88 & 56.56 & 20.0 & 23.44 & $\mathrm{C}$ \\
\hline $30-60$ & 1.07 & 31.40 & 21.20 & 1.40 & 42.84 & 54.56 & 17.0 & 24.44 & $\mathrm{C}$ \\
\hline $60-90$ & 1.08 & 29.60 & 22.08 & 1.16 & 26.17 & 62.56 & 17.0 & 21.44 & $\mathrm{C}$ \\
\hline
\end{tabular}

EC : Elektriksel iletkenlik (Electrical conductivity), TK: Tarla Kapasitesi (Field capacity)

SN: Solma Noktası (Wilting point), As: Hacim Ağırlığı (Bulk density)

Çizelge 2. Sulama suyunun bazı kimyasal özellikleri (Şimşek, 2015)

Table 2. Some chemical properties of irrigation water (Simsek, 2015)

\begin{tabular}{|c|c|c|c|c|c|c|c|c|c|c|}
\hline \multirow{2}{*}{ 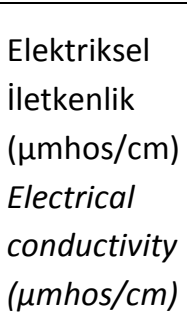 } & \multicolumn{4}{|c|}{$\begin{array}{l}\left.\text { Katyonlar (me } \mathrm{L}^{-1}\right) \\
\left.\text { Cations (me } \mathrm{L}^{-1}\right)\end{array}$} & \multicolumn{4}{|c|}{$\begin{array}{l}\text { Anyonlar }\left(\mathrm{me} \mathrm{L}^{-1}\right) \\
\text { Anions }\left(m e L^{-1}\right)\end{array}$} & \multirow{2}{*}{$\begin{array}{l}\mathrm{pH} \\
\text { değeri } \\
\mathrm{pH} \\
\text { value }\end{array}$} & \multirow{2}{*}{$\begin{array}{l}\text { Sulama suyun } \\
\text { sınıfi } \\
\text { Irrigation } \\
\text { water } \\
\text { classification }\end{array}$} \\
\hline & $\mathrm{Ca}^{++} \mathrm{Mg}^{++}$ & $\mathrm{K}^{+}$ & $\mathrm{Na}^{+}$ & $\begin{array}{l}\text { Top. } \\
\text { Total }\end{array}$ & $\mathrm{HCO}_{3}{ }^{-}$ & $\mathrm{Cl}^{-}$ & $\mathrm{SO}_{4}^{--}$ & $\begin{array}{l}\text { Top } \\
\text { Total }\end{array}$ & & \\
\hline 1080 & 1.98 & 0.02 & 0.25 & 2.25 & 0.90 & 0.60 & 0.75 & 2.25 & 7.0 & $\mathrm{C}_{3} \mathrm{~S}_{1}$ \\
\hline
\end{tabular}

Harran Ovası, yarı-kurak iklim kuşağında bulunmaktadır. Yazları sıcak ve kurak, kışlar ise ılık ve az yağışlı geçmektedir. Planlamada uzun yıllar iklim değerleri kullanılırken, değerlendirmede ise 2015 yılı iklim değerleri kullanılmıştır (Çizelge 3).

IRSIS bilgisayar yazılımında bulunan bitki kütüğünün oluşturulması için kullanılan mısır bitkisine ilişkin bitki karakteristikleri ise Çizelge 4'de sunulmuştur. 
Çizelge 3. Araştırma alanına ilişkin 1985-2014 uzun yıllar (U.Y) aylık ortalama ve 2015 yılı aylık ortalama iklim değerleri (Anonim, 2015)

Table 3. Years of research in the field 1985-2014 (U. Y) monthly average climate values and montly average climate values in 2015 (Anonymous, 2015)

\begin{tabular}{|c|c|c|c|c|c|c|c|c|}
\hline \multicolumn{2}{|c|}{$\begin{array}{l}\text { İklim } \\
\text { parametreleri } \\
\text { Climate } \\
\text { parameters }\end{array}$} & \multirow{2}{*}{$\begin{array}{l}\text { En yüksek } \\
\text { sıcaklık } \\
\text { Maximum } \\
\text { temp. } \\
\left({ }^{\circ} \mathrm{C}\right)\end{array}$} & \multirow{2}{*}{$\begin{array}{l}\text { En düşük } \\
\text { sıcaklık } \\
\text { Minimum } \\
\text { temp. } \\
\left({ }^{\circ} \mathrm{C}\right)\end{array}$} & \multirow{2}{*}{$\begin{array}{c}\text { Ortalama } \\
\text { sıcaklık } \\
\text { Mean temp. } \\
\left({ }^{\circ} \mathrm{C}\right)\end{array}$} & \multirow{2}{*}{$\begin{array}{c}\text { Nem } \\
\text { Relative } \\
\text { moisture } \\
(\%)\end{array}$} & \multirow{2}{*}{$\begin{array}{c}\text { Rüzgâr } \\
\text { hızı } \\
\text { Wind } \\
\text { Speed } \\
\left(\mathrm{ms}^{-1}\right)\end{array}$} & \multirow{2}{*}{$\begin{array}{c}\text { Güneşlenme } \\
\text { süresi } \\
\text { (saat ve } \\
\text { ondalık) } \\
\text { Sunshine } \\
\text { (hours and } \\
\text { decimals) }\end{array}$} & \multirow{2}{*}{$\begin{array}{l}\text { Yağış } \\
\text { Rain } \\
(\mathrm{mm})\end{array}$} \\
\hline $\begin{array}{c}\text { Aylar } \\
\text { Months }\end{array}$ & $\begin{array}{l}\text { Yıl } \\
\text { Year }\end{array}$ & & & & & & & \\
\hline \multirow[t]{2}{*}{1} & 2015 & 11.1 & 2.8 & 6.2 & 67.3 & 0.9 & 3.7 & 84.6 \\
\hline & U.Y & 10.5 & 2.7 & 6.1 & 70.7 & 1.2 & 3.9 & 86.8 \\
\hline \multirow[t]{2}{*}{2} & 2015 & 12.6 & 4.4 & 7.7 & 72.4 & 0.9 & 3.3 & 101 \\
\hline & U.Y & 12.2 & 3.3 & 7.2 & 66.3 & 1.3 & 4.9 & 58.8 \\
\hline \multirow[t]{2}{*}{3} & 2015 & 17.6 & 6.5 & 11.9 & 51.2 & 1.2 & 5.7 & 78.7 \\
\hline & U.Y & 16.9 & 6.5 & 11.2 & 59.5 & 1.5 & 6.2 & 37.2 \\
\hline \multirow[t]{2}{*}{4} & 2015 & 22.1 & 10.4 & 15.7 & 50.3 & 1.3 & 7.8 & 24.6 \\
\hline & U.Y & 22.9 & 11.2 & 16.7 & 56.4 & 1.6 & 7.3 & 48.0 \\
\hline \multirow[t]{2}{*}{5} & 2015 & 30.1 & 23.2 & 21.1 & 32.4 & 1.7 & 10.1 & 10.5 \\
\hline & U.Y & 29.2 & 16.2 & 22.6 & 46.4 & 1.7 & 9.3 & 27.9 \\
\hline \multirow[t]{2}{*}{6} & 2015 & 34.6 & 20.6 & 27.8 & 35.1 & 1.8 & 12.3 & 0.6 \\
\hline & U.Y & 35.2 & 21.5 & 28.7 & 35.3 & 2.2 & 11.6 & 3.0 \\
\hline \multirow[t]{2}{*}{7} & 2015 & 39.9 & 26.1 & 34.3 & 25.4 & 1.6 & 12.4 & 0.0 \\
\hline & U.Y & 39.2 & 25.2 & 32.4 & 32.8 & 2.2 & 11.6 & 0.0 \\
\hline \multirow[t]{2}{*}{8} & 2015 & 38.3 & 24.6 & 31.5 & 36.4 & 1.6 & 11.2 & 0.0 \\
\hline & U.Y & 38.8 & 24.8 & 31.8 & 36.7 & 1.9 & 11.0 & 0.0 \\
\hline \multirow[t]{2}{*}{9} & 2015 & 36.4 & 23.6 & 29.9 & 30.3 & 1.8 & 9.0 & 0.0 \\
\hline & U.Y & 34.0 & 20.5 & 26.9 & 40.1 & 1.7 & 9.2 & 0.3 \\
\hline \multirow[t]{2}{*}{10} & 2015 & 27.7 & 17.1 & 22.4 & 50.4 & 1.0 & 6.1 & 58.5 \\
\hline & U.Y & 26.9 & 15.3 & 20.2 & 49.7 & 1.2 & 7.4 & 37.2 \\
\hline \multirow[t]{2}{*}{11} & 2015 & 20.2 & 9.7 & 14.0 & 47.9 & 1.1 & 6.3 & 7.8 \\
\hline & U.Y & 18.5 & 8.6 & 12.7 & 61.5 & 1.2 & 5.4 & 27.0 \\
\hline \multirow[t]{2}{*}{12} & 2015 & 14.4 & 4.6 & 8.6 & 50.9 & 1.1 & 4.7 & 22.0 \\
\hline & U.Y & 12.1 & 4.5 & 7.8 & 70.4 & 1.1 & 3.7 & 34.1 \\
\hline
\end{tabular}

Sulama zaman planlaması ve gerçek zamanlı değerlendirmesi IRSIS bilgisayar yazılımı kullanılarak yapılmıştır. (Raes ve ark., 1988; Kodal, 1996; Tahmaz Koçak, 2006; Tuylu, 2010; Uçar, 2010; Tuylu ve UI, 2015). Sulama Zaman Planları parsel düzeyinde yetiştirilen herhangi bir bitki için bölgenin iklim koşulları, toprak özellikleri, yetiştirilen bitkinin karakteristikleri, çiftçi istekleri, kullanılan sulama yöntemi ile sulama sisteminin özellikleri göz önüne alınarak yeterli veya yetersiz su koşullarına göre IRSIS bilgisayar yazılımı kullanılarak elde edilir Diğer yandan, gerçekleşen sulamayı değerlendirebilen ve gerçekleşmiş sulama değerlerini kullanarak bir sonraki sulama dönemi için sulama planlaması yapabilen bir yazııımdır (Kodal, 2002). Çalışmada, referans bitki su tüketimi değerleri Penman-Monteith (FAO Modifikasyonu) yöntemi ile hesaplanmıştır. Mısır bitkisinin gerçek zamanlı sulama değerlendirmesinde ise 2015 yılı Class A Pan buharlaşma değerleri kullanılmıştır. 
Çizelge 4. IRSIS bilgisayar yazılımında bitki kütüğünün oluşturulması için kullanılan mısır bitkisine ilişkin bitki karakteristikleri (Anonim, 1998)

Table 4. The thief of the log of the plant that are used in Computer Software for the creation of maize plants plant characteristics (Anonymous, 1998)

\begin{tabular}{|c|c|c|c|c|c|c|}
\hline $\begin{array}{l}\text { Bitki } \\
\text { Plant }\end{array}$ & $\begin{array}{l}\text { Bitki karakteristikleri } \\
\text { Plant characteristics }\end{array}$ & $\begin{array}{l}\text { İlk dönem } \\
\text { First period }\end{array}$ & $\begin{array}{c}\text { Gelişme dönemi } \\
\text { Development } \\
\text { period }\end{array}$ & $\begin{array}{l}\text { Orta dönem } \\
\text { Middle } \\
\text { period }\end{array}$ & $\begin{array}{c}\text { Son } \\
\text { dönem } \\
\text { Last } \\
\text { period }\end{array}$ & $\begin{array}{c}\text { Toplam } \\
\text { Total }\end{array}$ \\
\hline \multirow{4}{*}{$\begin{array}{l}\text { Misır } \\
\text { Maize }\end{array}$} & $\begin{array}{l}\text { Dönem gün sayısı } \\
\text { The number of days } \\
\text { in the period }\end{array}$ & 25 & 30 & 50 & 25 & 130 \\
\hline & $\begin{array}{l}\text { Bitki katsayısı (kc) } \\
\text { Crop coefficient (kc) }\end{array}$ & 0.40 & - & 1.10 & 0.55 & - \\
\hline & $\begin{array}{l}\text { Kök derinliği (m) } \\
\text { Root depth (m) }\end{array}$ & 0.20 & 0.20 & 0.60 & 0.60 & - \\
\hline & $\begin{array}{l}\text { Verim faktörü (ky) } \\
\text { Yield factor (ky) }\end{array}$ & 0.40 & 1.50 & 0.5 & 0.2 & - \\
\hline
\end{tabular}

\section{Araştırma Bulguları ve Tartışma}

Çalışma sulama zamanı planlamasında ve değerlendirmesinde mısır bitkisi kök bölgesindeki nem değişimlerine ilişkin sonuçlar Şekil 2 ve Şekil 3’ de sunulmuştur.
Planlamada sulama aralığı 4 gün olup toprakta azalan nem her sulamada tarla kapasitesine çıkarılmışır. Planlamada derine sızım $114.2 \mathrm{~mm}$ olup değerlendirmede ise $397.4 \mathrm{~mm}^{\prime}$ dir.

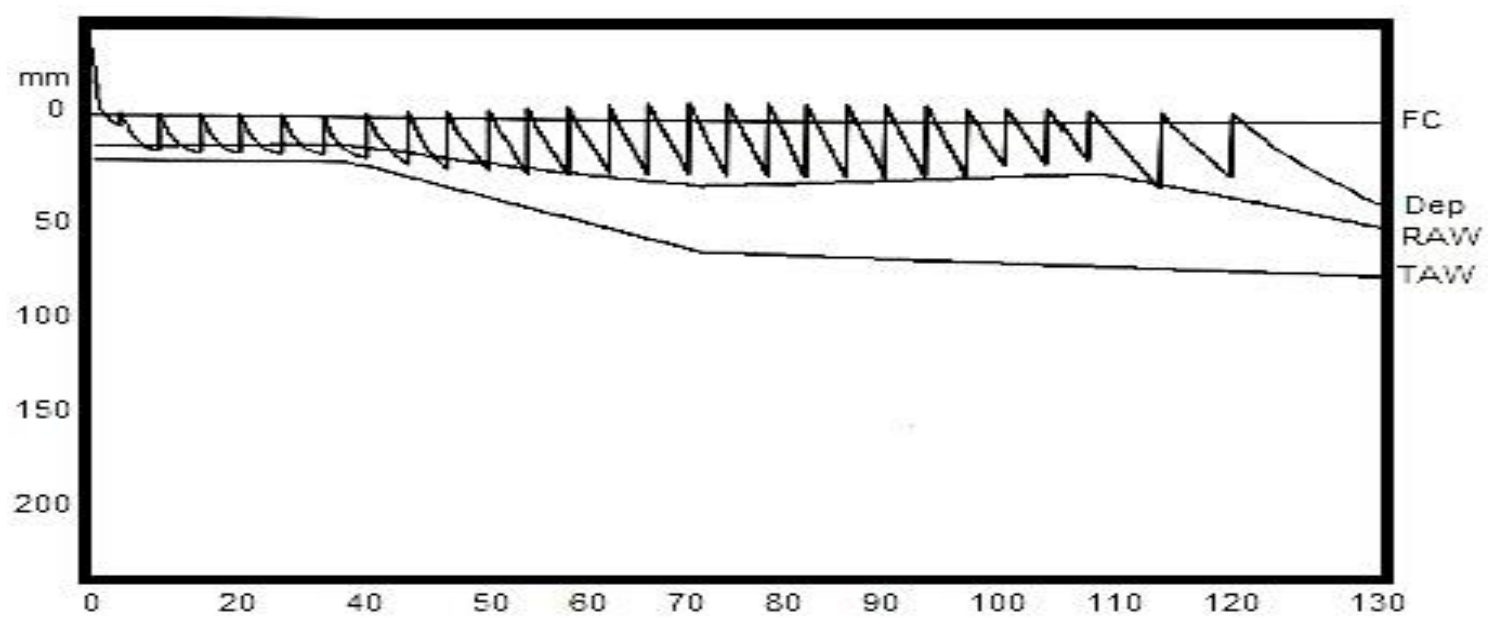

Şekil 2. Sulama zamanı planlamasında bitki kök bölgesindeki nem değişimi

Figure 2. Moisture changes in the root zone for irrigation scheduling plant 


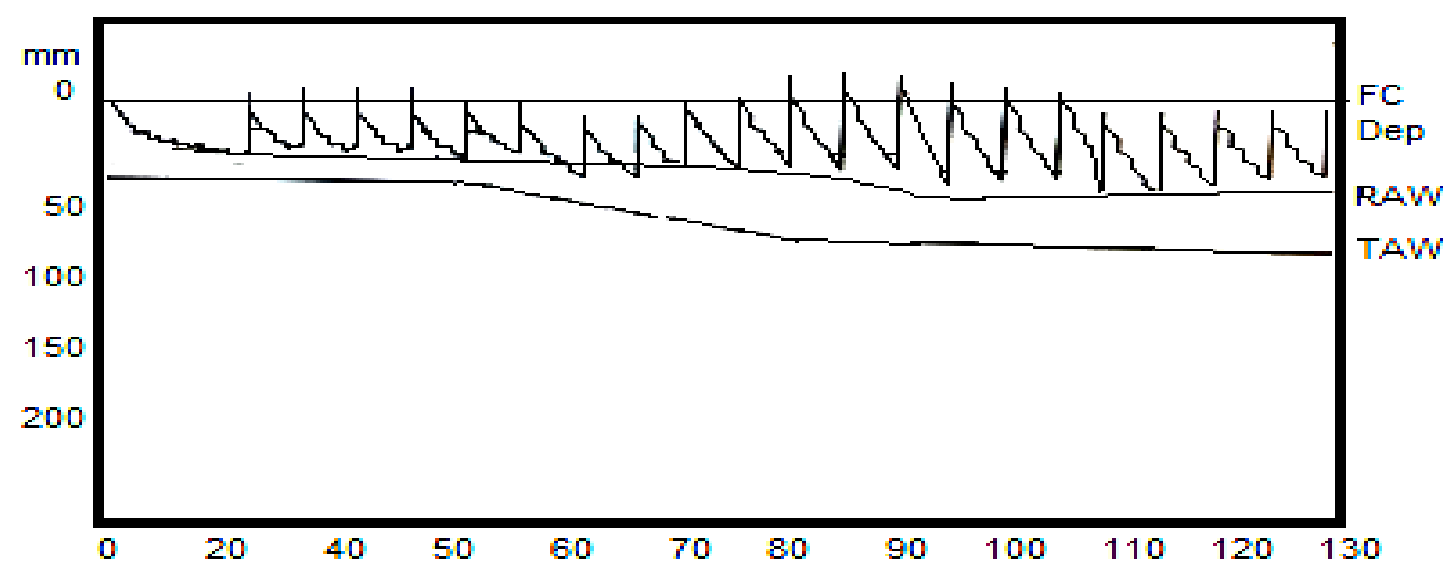

Şekil 3. Sulama zamanı değerlendirmesinde bitki kök bölgesindeki nem değişim Figure 3. Moisture changes in the plant root zone irrigation time for the assessment

Çizelge 5. Planlama ve değerlendirmeye ilişkin karşılaştırmalar Table 5. Comparisons for planning and evaluation

\begin{tabular}{|c|c|c|c|c|c|}
\hline & $\begin{array}{l}\text { Sulama suyu } \\
\text { miktarı } \\
(\mathrm{mm}) \\
\text { Irrigation water } \\
\text { amount (mm) }\end{array}$ & $\begin{array}{c}\text { *ETa ETm }{ }^{-1} \\
(\%)\end{array}$ & $\begin{array}{c}* * Y a Y^{-1} \\
(\%)\end{array}$ & $\begin{array}{c}\text { Su uygulama } \\
\text { randımanı (\%) } \\
\text { Water application } \\
\text { efficiency (\%) }\end{array}$ & $\begin{array}{c}\text { Derine } \\
\text { sızma } \\
(\mathrm{mm}) \\
\text { leakage } \\
(\mathrm{mm})\end{array}$ \\
\hline $\begin{array}{l}\text { Planlama } \\
\text { Planning }\end{array}$ & 711.1 & 1 & 99.5 & 98.9 & 114.2 \\
\hline $\begin{array}{l}\text { Değerlendirme } \\
\text { Assesment }\end{array}$ & 989 & 1 & 100 & 60 & 397.4 \\
\hline
\end{tabular}

* Ya $\mathrm{Ym}^{-1}$ : Gerçek verim miktarının maksimum verim miktarına oranı (The ratio of actual yield to maximum yield)

**ETa ETm-1: Gerçek bitki su tüketiminin, maksimum bitki su tüketimine oranı (The ratio of actual evapotranspiration to maksimum evapotranspiration)

Araştırmada, sulama suyu miktarı planlamada $711.1 \mathrm{~mm}$ olarak elde edilmiştir. Ancak, 2015 yılı için gerçekleşen sulama uygulamasında sulama suyu miktarı 989 mm'dir. Buna göre, su uygulama randımanı planlamada \% 98.9 ve değerlendirmede \% 60 olarak belirlenmiştir. Kırnak vd., (2002), damla sulama sistemi ile optimum sulama suyu miktarını 1999 yılı için 1215 mm ve 2000 yılı için 1295 mm olarak uygulamıştır. Su uygulama randımanı \% 98 olarak belirlenmiştir. Kırnak vd. (2002) tarafından yapılan araştırmada gerçek su tüketimi (ETa) 1320 mm iken, 2015 yılı için yapılan değerlendirmede elde edilen gerçek bitki su tüketimi (ETa) değeri 956.4 mm'dir. Diğer yandan çalışmada, planlanan ve gerçekleşen sulamaya göre verim kaybı yaşanmamıştır. $\mathrm{YaYm}^{-1}$ oranı planlamada \% 99.5 ve değerlendirmede \% 100 olarak elde edilmiştir. Kırnak vd., (2002) ise, $\mathrm{YaYm}^{-1}$ oranı değerlendirmede \% 100 olarak belirlemiştir.

\section{Sonuçlar}

Çalışmada, 2015 yılı için Harran Ovası'nı temsil edecek şekilde seçilen alanda mısır bitkisi (Zea mays L.) yetiştiriciliği amacıyla sulama zamanı planlaması yapılmış ve aynı yıl gerçekleşen sulama planlaması ile karşılaştırılmıştır. Sulama uygulamalarındaki hataların ortaya konması ve eksikliklerin giderilmesi yönünden bu tip çalışmaların yapılması önemlidir. Gerek bilimsel 
araştırmalar gerekse çiftçi düzeyindeki uygulamalarda mısır bitkisinin sulanmasında elde edilecek verim (\% 100) güvenilirdir. Ancak, sulama yönünde uygulamada fazla suyun kullanımı söz konusudur. Diğer bir deyişle derine sızan su miktarı fazla olup su uygulama randımanı (\% 60) düşüktür. Bitki vejetasyon dönemlerinde kısıt uygulanması, özellikle bitki koçanı dolumundan sonra, sulama aralığının arttırılması ve sulama suyu miktarının azaltılması, önerilmiştir.

\section{Ekler}

Bu çalışma, 12-15 Nisan 2016 tarihleri arasında Antalya'da 13. Ulusal Kültür teknik Kongresi'nde sözlü bildiri olarak sunulmuştur, ancak tam metin olarak basılmamıştır.

\section{Kaynaklar}

Anonim, 2015. Şanlıurfa Meteoroloji il Müdürlüğü İklim Verileri, Şanlıurfa.

Anonim, 1998. Crop Evapotranspiration Guidelines for Computing Crop Water Requirements, FAO Irrigation and Drainage Paper, 56, 300s.

Raes, D., Lemmens, H., Van Aels, P., Bulcke, M.V., Smith, M., 1998. IRSIS, Irrigation Scheduling Information System 1. Katholieke. Universiteit Leuven. Belgium.

Smith, M., 1992. Cropwat, A Computer Program for Irrigation Planning and Management. FAO Irrigation and Drainage Paper 46, Rome 126p.

Kendirli, B., 2001. Harran Ovası Sulama Birliklerinde Antepfıstığının Sulama Planlaması. Ankara Üniv. Zir. Fak. Tar. Bil. Dergisi, 7 (4): 114-120.

Kırnak, H., Gençoğlan, C., Değirmenci, V., 2002. Harran Ovası Koşullarında Kısıntıı Sulamanın II.Ürün Mısır Verimine Ve Bitki Gelişimine Etkisi. Atatürk Üniv. Zir. Fak. Tar. Bil. Dergisi, 34(2), 117-123.
Kodal, S., 1996. Ankara Beypazarı Ekolojisinde Yeterli ve Kısıtlı Su Koşullarında Sulama Programlaması İşletme Optimizasyonu ve Optimum Su Dağıtımı. Bilimsel Araştırmalar ve incelemeler. Ankara Üniversitesi Ziraat Fakültesi Yayınları, Ankara, 807, 69s.

Kodal, S., 2002. Sulama Programlama Teknikleri. Yüksek Lisans Ders Notu, Ziraat Fakültesi, Tarımsal Yapılar ve Sulama Bölümü, Ankara, 100s.

Kodal, S., Köksal, E.S., Tüzün M, Demir A.O, Özbek, Y., 2003. Sulama Şebekelerinin Yönetiminde Planlı Su Dağıtımı Esasları ve Bilgisayar Yazılımlarının Önemi. I. Ulusal Su Mühendisliği Sempozyumu, 22-26 Eylül, Gümüldür, İzmir.

Özcan, F., Tuylu, I. G., 2015. Harran Ovası Kurtuluş Sulama Birliğinde Su Kullanım Etkinliğinin Belirlenmesi. Üniversite Öğrencileri Yurt İçi Araştırma Projeleri Destek Programı, Şanlıurfa.

Şimşek, M., 2015. Harran Üniversitesi Ziraat Fakültesi, Tarımsal Yapılar ve Sulama Bölümü, Ders Notları, Şanlıurfa.

Tahmaz Koçak P., 2006, Asartepe Sulama Birliği Alanında Planlı Su Dağıtım Esaslarının Belirlenmesi. Doktora Tezi, Ankara Üniversitesi Fen Bilimleri Enstitüsü, 174s.

Tuylu, G.I., 2010, Gediz Havzası Sarıkız Sulama Birliği Sulama Sisteminin İşletimi Üzerine Model Yaklaşımı. Doktora Tezi, E.Ü. Fen Bilimleri Enstitüsü, 130s.

Tuylu, G.i., UI, M.A., 2015. Gediz Havzası Sarıkız Sulama Birliği'nde Mısır ve Bağ Bitkileri için Optimum Sulama Zaman Planlarının Hazırlanması. Harran Tarım ve Gıda Bilimleri Dergisi, 19 (4): 187-198.

Tarı, A.F., 2015. Harran Üniversitesi Ziraat Fakültesi. Tarımsal Yapılar ve Sulama Bölümü, Ders Notları, Şanlıurfa.

Uçar, Y., 2010. Isparta Koşullarında IRSIS Bilgisayar Yazılımı ile Elmanın Sulama Zaman Planlaması. Selçuk Tarım ve Gıda Bilimleri Dergisi, 24(4): 76-81. 